\title{
Em Defesa da Categoria de Voz Média no Português*
}

(In Defense of the Middle Voice Category in Portuguese)

\author{
Roberto Gomes CAMACHO \\ (UNESP - São José do Rio Preto)
}

\begin{abstract}
Middle voice represents an inflexional category of classical Indo-European languages with the function of expressing states of affairs which affect the subject of the verb or its interests. In Portuguese there is a set of predicates, formally identified by an anaphorical but non-coreferential use of the pronoun 'se', which supports the notion of middle diathesis. This paper aims at providing formal, semantic and typological evidences in order to postulate a distinction between middle and reflexive-reciprocal constructions.
\end{abstract} KEY-WORDs: Voice; Diathesis; Middle Voice; Reflexive-reciprocal Voice.

REsumo: A voz média representa uma categoria flexional das línguas clássicas indoeuropéias com a função de expressar estados de coisas que afetam o sujeito do verbo ou seus interesses. O português dispõe de um conjunto de predicados, formalmente identificados pelo uso anafórico e não-correferencial do pronome 'se', em que se sustenta a noção de diátese medial. Este trabalho pretende fornecer evidências formais, semânticas e tipológicas para postular uma distinção entre construções médias e reflexivo-recíprocas. PalavRas-CHave: Voz; Diátese; Voz Média; Voz Reflexivo-recíproca.

\section{A relevância da expressão medial no português}

Além de diferirem tipologicamente de acordo com os padrões de atribuição de caso aos argumentos nucleares de sentenças transitivas e intransitivas, os sistemas ergativo-absolutivos e nominativo-acusativos in-

\footnotetext{
* Este trabalho é resultado de pesquisa desenvolvida no projeto Construções de voz média (CNPqProc. 301185/92-1 - Bolsa de Produtividade de Pesquisa). Sua forma final tem um grande débito com os pareceristas anônimos da DELTA, cujas sugestões agradeço. Os problemas que ainda restam são de minha inteira responsabilidade.
}

D.E.L.T.A., 19:1, 2003 (91-122) 
corporam esquemas que reorganizam a atribuição de relações gramaticais nucleares a papéis temáticos particulares. A construção passiva representa um mecanismo próprio das línguas acusativas e a construção antipassiva, a contraparte da passiva nas línguas ergativas. Tais formas de expressão, vistas como processos derivacionais, sinalizam rearranjos da organização sintática básica de uma sentença, ao intercambiarem as relações gramaticais de argumentos que representam certos papéis.

Este trabalho interessa-se, todavia, pela relação do sujeito com situações expressas em sentenças básicas, não em sentenças derivadas. Entende Klaiman (1988), que ao sujeito de sentenças básicas só se permitem dois status conceituais, o de 'iniciador e/ou controlador' e o de 'entidade afetada', cabendo a uma alternância formal na morfologia verbal indicar qual dos dois status é atribuído ao sujeito da sentença. A essas formas alternativas Klaiman se refere como diátese e ao sistema ao qual elas pertencem, como voz, de acordo com a perspectiva assumida por Benveniste (1976) para o exame das línguas clássicas indo-européias (doravante IE).

A hipótese sugerida por Klaiman (1988) foi aplicada ao espanhol e ao inglês por Arce-Arenales et al. (1994). Pretende-se demonstrar aqui que essa categoria básica de voz, de que dispõem várias línguas modernas, está presente também no português. Defende-se fundamentalmente a idéia de que o português, como língua nominativo-acusativa, trata sujeitos de sentenças sintaticamente ativas como semanticamente afetados ou não afetados pelo estado de coisas representado na predicação. As sentenças formalmente ativas cujo sujeito é não-afetado serão consideradas sentenças básicas de diátese ativa, enquanto as sentenças formalmente ativas cujo sujeito é afetado serão consideradas sentenças básicas de diátese média.

Em geral, a construção mais básica ou primária para a representação da relação sujeito/verbo é a sentença de voz ativa, denominação que procede do fato de ser o evento tratado como uma ação, ou atividade de determinada entidade, representada pelo sujeito, de quem pelo menos parte o evento na representação lingüística (Câmara Jr 1977). Já o termo voz média, tal como originalmente empregado, designa uma categoria flexional que, do ponto de vista formal, constituía, nas línguas clássicas IE, um conjunto paradigmático de sufixos verbais com uma função semântica bem delineada: expressar eventos em que a ação ou o estado afeta o sujeito do verbo ou seus interesses (Lyons 1979: 373). 
Era morfológica a expressão formal da diátese nas línguas clássicas IE, especialmente no grego e no sânscrito. Segundo Benveniste, (1976), como a marca de voz se associa às de pessoa e de número para caracterizar a desinência verbal, havia duas unidades formais no verbo: uma reúne um conjunto de três referências, cada qual situando o sujeito em relação ao estado de coisas: pessoa/não-pessoa, individualidade/pluralidade, diátese interna/diátese externa; a outra unidade formal se destina a localizar o estado de coisas em si em relação ao tempo e ao modo de desenvolvimento.

Embora a categoria de voz básica no português não apresente expressão desinencial, a morfologia verbal permite distinguir a diátese ativa da média mediante o uso do clítico se em construções sintáticas alternativas com a expressão de diferentes funções semânticas, mais ou menos similares à diátese das línguas clássicas $\mathrm{IE}^{1}$.

Ao estender a noção ao português, Câmara Jr.(1972) não se distancia muito da definição de Lyons; o que chama medial corresponde morfossintaticamente a uma construção em que à forma do verbo na voz ativa se acrescenta um pronome adverbal átono, referente à pessoa do sujeito, e a função semântica que veicula é a de uma integração no estado de coisas que dele parte.

Mencionando Brugmann, Câmara Jr. (1972: 182-3) fornece três subcategorias de voz média (medial, para o autor): a média reflexiva, a média recíproca e a média dinâmica. Tanto na média reflexiva, quanto na recíproca, a construção não-pronominal com objeto autônomo, isto é, não correferencial ao sujeito, mantém inalterada a significação verbal, sempre numa forma ativa.

Já na média dinâmica, a pessoa do sujeito, sob a forma do clítico, reaparece no predicado como o centro de um estado de coisas que dele parte, mas que não sai de seu âmbito, eliminando-se, assim, o objeto sobre o qual ela recairia num típico evento transitivo:

(1) a. eu me levantei.

1 Nas línguas IE, a noção gramatical que interpreta a integração do sujeito no estado de coisas era assinalada por flexões especiais próprias, numa construção chamada média pelos gramáticos gregos (porque distante do pólo da ativa e do pólo da passiva). Em latim, os verbos depoentes provêm em parte dessas flexões mediais, mas já sem a sua noção específica, o que propiciou a 
Diferentemente das estruturas reflexivas e recíprocas, a construção com pronome autônomo altera a significação verbal; observe-se que em (1b) o predicado passa a ter um valor causativo e um significado comparável ao de "erguer".

(1) b. eu o levantei.

Devido ao compartilhamento da mesma morfologia, construções médias, construções reflexivas e construções recíprocas são potencialmente ambíguas. Observe-se uma ocorrência tratada tipicamente como voz reflexiva em (2a) e outra, tratada tipicamente como recíproca em (2b).

(2) a. e a melhor maneira que ele encontrava pra se defender era atacando (EF-RJ-379)

b. eles se ah... complementam andam juntos (EF-RE-337)

Ambas as construções de (2) permitem uma formulação alternativa na voz ativa com o mesmo valor semântico:

(3) a. a melhor maneira que ele encontrava para defender sua família era atacando

b. eles complementam o salário com horas extras.

O compartilhamento da mesma expressão formal torna necessário, com verbos no plural, o acréscimo de informação contextual para distinguir construções reflexivas de recíprocas. Observe-se uma interpretação mais provavelmente recíproca em (4a) e uma interpretação mais provavelmente reflexiva em (4b):

(4) a. Os dois irmãos se vêem sempre na escola.

b. Os dois irmãos se vêm sempre em apuros na escola.

De qualquer modo, o sistema morfossintático dispõe de mecanismos para diferenciá-las. A sentença (5a) constitui um exemplo de reflexiva nãoambígua e a sentença (5b), um exemplo de recíproca não-ambígua.

passagem desses verbos para a ativa nas línguas românicas, e o desenvolvimento da construção pronominal para representar a noção perdida. Verbos depoentes tinham uma forma especial distinta da ativa; era idêntica à da passiva, mas com outra significação: indicava um valor reflexivorecíproco ou medial (cf. Câmara Jr 1972). 
(5) a. Eles se vêem a si mesmos no espelho.

b. Eles se vêm um ao outro no espelho.

A despeito da morfologia compartilhada, é perfeitamente possível separar em um paradigma as construções reflexivas e recíprocas e em outro as construções médias.

O português dispõe de itens lexicais específicos, todos verbos inerentemente pronominais, para representar essas categorias semânticas de certa universalidade nas línguas, o que oferece um bom indício para postularse a existência de uma categoria morfossintática de voz média ${ }^{2}$. É necessário, entretanto, verificar se esses tipos de predicados têm algum traço semântico comum que permita identificá-los como membros de um paradigma unitário.

\section{A pertinência teórica da distinção entre construções médias e reflexivo-recíprocas}

É necessário esclarecer inicialmente que este trabalho se baseia numa perspectiva trans-sistêmica da morfologia média, proposta tanto por Kemmer (1994) quanto por Klaiman (1988), cujas propriedades podem aplicar-se também ao português. Kemmer enumera uma lista de dez tipos de situações altamente relevantes, denominadas tipos de situação medial, cujo correlato formal é a presença de alguma marcação: cuidados corporais (Latim lavo- $\boldsymbol{r}$, português lavar-se), movimento não-translacional (Latim: reverto-r, português: virar-se); mudança na postura corporal (alemão: sich binlegen; português: deitar-se); movimento translacional (francês: s'en aller; português: ir-se); eventos naturalmente recíprocos (latim: amplecto- $\boldsymbol{r}$, português: abraçar-se); médias de emoção (latim: irasco- $\boldsymbol{r}$, português: irritar-

2 O português desenvolveu um conjunto muito diversificado de verbos pronominais bivalenciais, com o segundo argumento na função de oblíquo. Esse SN complemento, regido por preposição, não representa uma entidade afetada e é por causa desse baixo grau de centralidade com o predicado que esse participante assume a função sintática de oblíquo e não a de um argumento interno, diretamente dominado pelo SV. Uma taxionomia desse tipo de verbo pronominal com base em critérios de natureza sintática aparece em Nunes (1995), que tem como objetivo examinar a distribuição de ausência ou a presença de clítico anafórico, de uma perspectiva diacrônica, em relação aos tipos de verbos, além de outros fatores condicionadores. 
$\boldsymbol{s e}$ ); discurso emotivo (latim: quero- $\boldsymbol{r}$, português: queixar-se); média de cognição (latim: medito- $\boldsymbol{r}$, sem expressão no português; alternativa: lembrar-se); eventos espontâneos (francês s'evanouir; sem tradução no português; alternativa: originar-se); média indireta (grego clássico: kta-sthai: adquirir para si próprio, sem tradução em português).

Esses estados de coisas são muito recorrentes em línguas diversas, mantendo nelas o mesmo comportamento sintático-semântico; assim, se existirem pelo menos dois desses subtipos na mesma língua, eles serão expressos pelo mesmo marcador. Esse fato sugere que a média é uma categoria lingüística potencial capaz de manifestar-se gramaticalmente. Além disso, Kemmer (1994) demonstra que esses tipos de estados de coisas são semanticamente distintos de construções com marcação reflexiva. Línguas que dispõem de um marcador medial para representar gramaticalmente esses estados de coisas devem ser consideradas sistemas mediais.

O português é um sistema medial, aspecto em que difere do inglês, por exemplo, que expressa os mesmos tipos de estados de coisas acima mencionados mediante o uso de formas verbais intransitivas, destituídas de marcação formal, como dress, ou uma construção derivada alternativa, como get dressed (cf. Kemmer 1994: 183-4).

A associação da medialidade com intransitividade no inglês pode constituir evidência indireta e comparativamente reveladora para postular que o clítico de verbos como barbear-se, vestir-se, lavar-se sejam considerados marcadores mediais e não pronomes reflexivos. Para essa classe de verbos, o inglês não admite o reflexivo, que aparece como forma marcada apenas quando o sujeito é não-humano, como mostra, por exemplo, o par John washed/Tiger was washing himself, em que 'John' é um ser humano e 'Tiger' o nome de um gato. Haiman (1983) entende que a razão pela qual muitas línguas não marcam ações corporais como reflexivas é a expectativa de que seres humanos executem esse tipo de evento em favor de si mesmos e não de outras pessoas; em conseqüência disso, o objeto não-marcado não requer codificação.

O português dispõe de um elenco considerável de verbos intransitivos em que iniciador e entidade afetada convergem no sujeito, como desaparecer, evoluir etc, por um lado, e cair, morrer etc, por outro. Mesmo assim, esses predicados não se enquadram no sistema de diátese medial, não só por serem destituídos de marcação formal, mas também por não apresentarem 
contraparte transitiva, que permita algum tipo de seleção. Os que apresentam, como os dois últimos, não são cognatos, já que os transitivos semanticamente correspondentes, derrubar e matar respectivamente, não são relacionados aos intransitivos por regra de derivação lexical.

Assim, um verbo pronominal, como vestir-se, por exemplo, não será considerado uma instância de reflexividade, mesmo que haja um predicado causativo correspondente. A razão disso é que vestir-se representa uma situação de cuidado corporal, o que é por definição uma atividade própria da entidade iniciadora e/ou controladora do evento. O uso causativo é uma situação incomum, marcada, e só é possível de ser enunciada nas situações em que o iniciador do estado de coisas não está em condições de controlálo, como se observa em (6a-b) abaixo.

(6) a. Após o banho, tia vestiu o bebê com cuidado.

b. Depois que Antônio fraturou o braço, sua esposa o veste todos os dias.

Construções enfáticas, com o SP a si mesmo (a) soam estranhas em construções médias, a não ser que alguma situação especial esteja envolvida, como as de (7c-d). Essas sentenças requerem uma forma ainda mais pesada fonologicamente, que se traduz formalmente no uso do oblíquo tônico reforçado com os anafóricos mesmo e próprio:

(7) c. Antônio vestiu-se a si mesmo pela primeira vez após a cirurgia.

d. Antônio vestiu-se a si próprio não a seu irmão.

Assim, no português, em que o marcador reflexivo e o médio são idênticos, os únicos casos em que é viável uma marcação distintiva para a interpretação reflexiva, em contraste com a interpretação medial, é na situação contrastiva e/ou enfática, que requer o uso de si mesmo.

Em vista dessa posição, é útil esclarecer que se evitará usar aqui o termo 'reflexivo' para designar os diversos usos do clítico se. Como marcador medial, o clítico se ainda retém propriedades pronominais de acordo com suas origens no pronome reflexivo: formalmente ainda é parte do paradigma pronominal, correlacionando-se com outros membros da classe, embora o único traço nominal que lhe resta seja o de pessoa; além disso, ele participa regularmente das regras de colocação de clíticos que governam os prono- 
mes em geral. O marcador medial ainda mantém traços morfológicos e sintáticos tipicamente pronominais, mas sua forma de manifestação sintática e semântica não é idêntica à do marcador reflexivo-recíproco; nas construções médias, o clítico não permite, por um lado, comutações com outros termos possíveis do mesmo paradigma e, por outro, não estabelece com o sujeito uma relação semântica de correferência e sintática de coindexação, o que só seria possível se houvesse duas posições estruturais disponíveis para serem preenchidas por SNs referencialmente idênticos.

Nas construções reflexivo-recíprocas, o clítico se caracteriza por uma simetria de traços número-pessoais com o termo na posição de sujeito, com o qual se acha obrigatoriamente coindexado, pelo menos na variedade culta ${ }^{3}$. Sobre isso, afirmam Ilari et alii:

Oprincipal fenômeno da coindexação obrigatória, em português, é a reflexivização, meio standard para coindexar certos anafóricos (em particular o pronome reflexivo/recíproco 'se') com sintagmas nominais, dadas certas condiçoes estruturais da oração ou do período (Ilari et al. 1996: 134).

O fato de não constituir uma posição sintática preenchível aproxima as construções médias das construções impessoais: há em ambas as classes um marcador morfológico sem posição valencial no esquema de predicado. Observe-se o exemplo (8) abaixo.

(8) \é que ela realmente procura se aperfeiçoa(r) dentro daquilo que faz (DID-POA-045)

Em (8), o pronome se não é um coindexador. Se considerarmos que aperfeiçoar é um verbo intransitivo, o pronome se

exerce ao contrário um papel que pode ser melhor captado se, reportando-nos ao nível lexical, o entendermos como indicação de que um predicado de $\boldsymbol{n}$ argumentos, sofreu redução para $\mathbf{n}-\mathbf{1}$ argumentos, devendo o argumento que falta ser procurado entre os sintagmas nominais presentes (...) Se não fosse arriscado dar mais um rótulo à partícula se, que a gramática tradicional já castigou espetando-lhe tantas etiquetas sem no fundo entendê-la, falaríamos de bom grado aqui em 'se medializador'. Deve ter sido pela via desses 'ses medializadores' que surgiu em português uma conjugação intrinsecamente pronominal, onde o pronome se já não exprime qualquer papel profundo (Ilari et al, 1996: 163).

\footnotetext{
3 É bom lembrar que é comum na variedade falada não-padrão a generalização da forma clítica de $3^{\text {a }}$ pessoa para todas demais: eu se feri, nóis se feriu, etc.
} 
O correlato morfossintático de uma construção média são, portanto, sentenças com verbos intrinsecamente pronominais cujo clítico já não representa nenhum participante no esquema valencial. No caso de vestir-se, o léxico do português dispõe de duas entradas, uma pronominal, que representa a interpretação média, e outra não-pronominal, que representa a interpretação causativa. O efeito semântico está no fechamento do predicado sobre seu sujeito, valor semântico que já se supõe estar presente na construção reflexivo-recíproca. A diferença, entretanto, é que nesta o clítico é simultaneamente anafórico e correferencial ao sujeito, enquanto na média o clítico é unicamente anafórico. O pronome reflexivo, que perdeu completamente seu estatuto argumental, pode ser considerado uma espécie de afixo pronominal que concorda em pessoa e número com o sujeito da sentença. Comparem-se (9a-c) e (10a-c):

(9) a. Maria viu o menino no espelho

b. Maria viu-se no espelho.

c. Maria viu-se a si mesma no espelho

(10) a. João se levantou.

b. João levantou a pedra.

c. ?João se levantou a si mesmo

Diferentemente dos reflexivos, não há comutação plausível entre o clítico e outro SN com manutenção de compatibilidade semântica, como comprovam os exemplos contidos em (9a-b) e (10a-b) acima. Além disso, enquanto (10c) soa um tanto estranha, o mesmo não se aplica a (9c). Segundo Benveniste (1976), ser o sujeito, ao mesmo tempo, centro e ator do evento (diátese interna) é condição para a construção média. É natural, portanto, que, quando o sujeito for ator e exterior ao evento, haja secundariamente uma forma ativo-transitiva do verbo; o evento não sendo dirigido ao sujeito, é transferido a outro termo, que é nesse caso o objeto. Isso ocorre em (9b), cuja leitura reflexiva é tipicamente marcada, já que ver pressupõe uma experiência sensorial inerentemente voltada para o outro; quando se dirige para a entidade experienciadora, o uso do predicado está comprometido com um contexto situacional em que exista algum objeto refletivo. 
Essas distinções formais fornecem um bom indício para se postular a existência de uma categoria morfossintática de voz média. É necessário, entretanto, verificar se esses tipos de predicados têm algum traço semântico comum que permita identificá-los como membros de um paradigma unitário. É o que se pretende discutir a seguir. Antes de iniciar a discussão, propriamente dita, vale a pena mencionar que a proposta de trabalho envolve a confirmação ou rejeição de três hipóteses interligadas, que se detalham na seção 3 com as respectivas justificativas teóricas.

Parte-se do princípio de que as construções médias constituem tipos semânticos bem definidos de predicados cujo sujeito detém a responsabilidade pelo desencadeamento do evento do qual é também o principal locus de seus efeitos. Em função da convergência desses dois status semânticos no sujeito, pode-se dizer que as construções médias fundem, na mesma entidade, Iniciador e Ponto de Chegada. As construções reflexivo-recíprocas são equivalentes às médias, em termos da convergência desses dois status semânticos, mas elas envolvem uma diferenciação conceitual da entidade referencial em duas subpartes discretas, traço que não se aplica às médias.

A correlação formal mais evidente dessa diferenciação semânticocognitiva está no diferente estatuto morfossintático do clítico marcador. $\mathrm{Se}$, por um lado, é simultaneamente anafórico e coindexado ao SN sujeito nas construções reflexivo-recíprocas, é, por outro, apenas anafórico, jamais coindexado, nas construções médias. Essa caracterização formal conduz à formulação de uma terceira hipótese, um tanto especulativa: há uma supressão do clítico a afetar somente as construções médias, o que induziria a pensar que o PB falado estaria passando de sistema de uma forma, em que os dois tipos de construção compartilham a mesma morfologia, para um sistema de duas formas, em que a ausência de clítico, marcaria a medialidade, enquanto a manutenção do clítico, a reflexividade.

\section{Em defesa da categoria de voz média no português}

\subsection{Convergência no sujeito dos status semânticos de iniciador/controlador e entidade afetada}

Como mencionado, as construções de voz média fazem parte de um domínio semântico, que inclui, de modo regular nas diversas línguas, subtipos específicos de estados de coisas. 
No levantamento prévio operado sobre corpus falado e escrito ${ }^{4}$, examina-se a incidência dessas classes semânticas nas construções médias. A grande maioria, 60,0\% das ocorrências (56/94) não se refere a nenhuma dessas categorias; trata-se de predicados tipicamente processivos, como tornar-se, encontrar-se, seguido de predicativo do sujeito, e outros como encarregar-se, candidatar-se, abster-se de etc, que não encontram classificação nos tipos de situação propostos por Kemmer (1994), assim como os ergativos, como organizar-se, generalizar-se, desenvolver-se etc. Os mais reincidentes foram as médias de emoção com 34,0\% (13/94), verbos de cognição e de evento recíproco, cada qual com 13,0\% (05/94), movimento translacional, com $16,0 \%$ (6/94), abaixo exemplificados:

(11) a. É também fácil descobrir como o bebê se consola quando irritado. (MA,T6, L111)

b. Lembre-se que a gente também tem a Quantum (A, T25, L7)

c. Cavaco reuniu-se com Ferreira do Amaral (MA, T2, L1)

d. Sendo assim, quem está mal retira-se. (MA, T4, L.52)

Segundo Benveniste (1976), ser o sujeito, ao mesmo tempo, centro e ator do evento (diátese interna) é condição para a construção de voz média nas línguas clássicas IE. É natural, portanto, que, quando o sujeito for ator e exterior ao evento, haja secundariamente uma forma ativo-transitiva do verbo; o evento não sendo dirigido ao sujeito, é transferido a outro termo, que, nesse caso, é o objeto. Essa característica da medialidade nas línguas clássicas IE parece aplicar-se à maioria dos verbos inerentemente pronominais do português, o que explica haver a fusão, numa única e mesma entidade, de dois diferentes papéis temáticos, conforme análise de Nunes (1995), ou dois diferentes status semânticos.

Como era comum nas línguas clássicas, o léxico do português dispõe de classes de verbos exclusivamente médios, ou media tantum, como queixar-se, apaixonar-se e de classes de verbos médios que se opõem a classes de verbos transitivos, como se vê, respectivamente em levantar-se x levantar, virar-se x virar. Diferentemente dos reflexivos, não há comutação plausível

4 O corpus escrito, extraído de jornais e revistas de grande circulação no Brasil e em Portugal, é constituído pelos seguintes gêneros: matérias assinadas (MA), anúncios (A), cartas do leitor (CL) e entrevistas (E) e o corpus falado é constituído por inquéritos do NURC. 
entre o clítico e outro SN com preservação de compatibilidade semântica, como comprovam os exemplos contidos em (12) e (13) abaixo.

(12) a. João virou-se.

b. João virou a pedra.

(13) a. João conduziu-se bem na cerimônia.

b. João conduziu bem a cerimônia.

É possível sustentar a hipótese de que os verbos pronominais são predicados básicos, tipicamente médios, e as formas causativas sem correspondência semântica, predicados derivados por uma regra lexical de aumento de valência.

Em função desse tipo de distribuição sintática do léxico, Bacelar do Nascimento e Martins (s/d.) propõem, como hipótese para o português contemporâneo, cinco subclasses formalmente distintas de predicados mediais: subclasse 1: verbos que só admitem a construção média, como queixar-se em (14a); subclasse 2: verbos que admitem, além da construção em -se, a construção resultativa com o auxiliar estar, como ressentir-se, estar ressentido, sem mudança de valência, como (14b); subclasse 3: verbos que, em virtude de diferenças sintático-semânticas, podem ser considerados diferentes itens lexicais, como comportar e comportar-se, em (14c); subclasse 4: verbos que, apesar da duplicidade de formulação sintática, apresentam o mesmo valor semântico como rir/rir-se, sem incidência no corpus; subclasse 5: verbos que apresentam homonímia sintática: por um lado, uma construção ativo-causativa, que permite oposição à voz passiva; por outro, uma construção média, pronominal, que tem por par correlativo a construção resultativa com estar, como apagar (14d).

(14) a. (...) designadamente, o PSD que antes ameaçava queixar-se a instancias internacionais se a lei fosse revista.(MA, T1, L13).

b. A sua vida sexual pode ressentir-se tanto durante a gravidez como no futuro. (MA, T5, L48)

c. Fale com seu gerente Bradesco e veja como seu filho vai se comportar como um anjinho (A, T3, L6)

d. (...) que corta o gás caso a chama se apague (A, T91, L4) 
A grande maioria de construções médias que o corpus manifesta ocorre com verbos da subclasse 3 (v. exemplo 14c), com uma incidência de 58,0\% (54/94), seguida por verbos da subclasse 5 (exemplo (14d), que mantêm freqüência de 36,0\% (34/94); os verbos da subclasse 1 compreendem apenas $4,0 \%$ do total de ocorrência (4/94), enquanto os da subclasse 2, apenas $2,0 \%(2 / 94)$.

É possível referir-se aos verbos inerentemente pronominais das subclasses 1, 2, como queixar-se, arrepender-se e levantar-se, como media tantum, já que não têm uma contraparte não-pronominal. Os predicados dessas subclasses não são certamente derivados por qualquer tipo de regra de formação de predicados, devendo, por isso, ser considerados como básicos e assim listados no léxico.

Predicados da subclasse 3, como importar/importar-se, interessar/interessar-se etc, também não podem ser incluídos em nenhuma regra de formação de predicados, constituindo cada qual uma entrada lexical própria sem correspondência semântica com algum outro predicado. Pode-se afirmar que as construções inerentemente pronominais dessas duplas são também casos de media tantum, como os das subclasses 1 e 2 .

Verbos da subclasse 4, como rir/rir-se, não constituem diferentes predicados, já que o estatuto valencial não se altera com a inserção do pronome expletivo; no entanto, a ocorrência variável do clítico indica claramente tratar-se de evento dinâmico que não sai do âmbito do sujeito.

Somente verbos da subclasse 5, como conscientizar-se, podem ser explicados adequadamente mediante uma regra de formação de predicados derivados (cf. Dik 1985), a partir do causativo. Observem-se os seguintes exemplos:

(15) a. O padre conscientizou Maria das dificuldades do casamento. (ativo-causativa)

b. Maria foi conscientizada pelo Padre das dificuldades do casamento. (passiva)

(16) a. Maria se conscientizou das dificuldades do casamento. (média)

b. Maria está conscientizada das dificuldades do casamento. (estativo-resultativa)

Em (15a-b), o predicado da sentença ativo-causativa é trivalencial, apresentando, por isso, contraparte passiva. Já a sentença de (16a) permite 
uma leitura tipicamente média, com um verbo inerentemente pronominal da subclasse 2; trata-se, nesse caso, de um predicado derivado por uma regra de redução de valência, semanticamente orientado para a entidade iniciadora que, no caso, mantém o status semântico de entidade afetada.

É interessante observar que um evento causativo exclui a construção reflexiva; o clítico se de (16a) não pressupõe reforço com a si mesma, mas com por si mesma, o que leva a interpretá-la como construção média. A reflexividade é muito mais restrita: está relacionada semanticamente a verbos não-causativos com SNs animados, daí a impossibilidade de uma construção reflexiva como (17b) :
(17) a. João cortou o bolo.
b. ?O bolo (se) cortou.
c. João se cortou.

Este é um bom argumento para considerar que deve ser preferencialmente média a interpretação de construções ergativas, como (18) abaixo, que exibem correspondência com predicados causativos.

(18) a. Do mesmo modo que um bebé acalma-se, geralmente, ao ouvir sons ritmados. (MA, T6,L87)

b. Sons ritmados acalmam o bebê.

c. O bebê se acalmou por causa dos sons ritmados.

A condição para a derivação de ergativas a partir de construções causativas é a de que sua rede temática inclua necessariamente um argumento na função semântica de causativo ou Força (Dik 1989), sons ritmados de (18b) e um argumento necessariamente afetado ou Meta (Dik 1989), que passa a ocupar a posição de sujeito sintático nas ergativas, um bebê, nas construções (18a) e (18b) (cf. Whitaker-Franchi 1991; Franchi \& Cançado $\mathrm{s} / \mathrm{d})$. A responsabilidade pelo acionamento do evento é exterior à entidade afetada. Essa condição não se aplica às construções reflexivas, pois a responsabilidade pela iniciação do estado de coisas mantém-se no âmbito da entidade afetada.

Eventos causativos requerem um causador externo virtual, mas é possível construir sentenças, como (18c), com a entidade causativa detematizada 
e reduzida à posição de oblíquo, e verbalizar o evento como auto-suficiente na rede causal. Nesse caso, a auto-suficiência do evento parece ser mais relevante para os propósitos comunicativos que a ação de uma causa externa controladora na função de sujeito (cf. Croft 1994), pressupondo certa responsabilidade da entidade afetada no desencadeamento do processo.

Para Klaiman, como se viu, no tipo médio de voz o sujeito, além de iniciador e/ou controlador, representa também o status de entidade afetada, conceito mais abrangente que o do papel temático de Meta (Dik 1989) ou Paciente. Em contraste com a média, sobre o sujeito da ativa, que é, de algum modo, o controlador do estado de coisas, não incidem os efeitos do evento. A representação da sentença ergativa correspondente parte de uma perspectiva em que a entidade afetada, também o ponto de partida do evento, não está sujeita a qualquer causa externa; essa característica, aliada à marcação morfossintática do clítico correspondente, torna evidente sua inserção na classe das médias.

Apesar dessa evidente inserção, não se deve limitar a medialidade às construções ergativas, que têm na afetação do sujeito o traço semântico mais distintivo, pois, se por um lado, as ergativas não implicam necessariamente a presença de causador externo, também, por outro, a classe de verbos pronominais monovalenciais não se restringe a estados de coisas [+ dinâmicos, -controlados $]^{5}$. A categoria medial inclui um paradigma de predicações controladas, em que uma entidade agentiva opera sobre si mesma, como levantar-se, virar-se, ajoelhar-se; inclui também uma classe de predicados de processos e estados cognitivos, como lembrar-se e interessar-se, respectivamente, que acarretam a participação de entidades experienciadoras. Há evidências dessa distribuição no corpus investigado, principalmente na incidência majoritária de predicados de processo $[+\mathrm{di}-$ nâmico,-controlado], 46,0\% (43/94); além dessa categoria, há 24,0\% (23/ 94) de predicados de posição [-dinâmico, + controlado], 16,0\% (15/94) de predicados de estado [-dinâmico, -controlado] e 14,0\% (13/94) de predicados de ação [+dinâmico, + controlado $]$, conforme se verifica respectivamente em $(19 \mathrm{a}-\mathrm{d})$.

5 Para um visão geral da tipologia semântica dos predicados aqui adotada, v. Dik 1989:89-109. 
(19) a. O resto organizou-se por si mesmo. (MA, T12, L45)

b. Um recém-nascido interessa-se em primeiro lugar pelos contornos e pelas fronteiras entre as cores. (MA, T6, L66).

c. O Colégio Cidade se dedica a aprimorar cada vez mais a formação de profissionais (A, T7, L1)

d. Fresco e de rápida absorção, ele permite que você se vista imediatamente após a aplicação. $(\mathrm{A}, \mathrm{T} 16, \mathrm{~L} 5)$

Assim, todos os casos de voz média do corpus manifestam predicados com argumento único afetado e todo o estado de coisas é tomado como não sendo o resultado da atuação de uma outra entidade causativa. A entidade referencial na função de sujeito é responsável pela iniciação do estado de coisas cujos efeitos então permanecem no âmbito dela mesma.

É necessário acrescentar que, formalmente, todos os predicados são mono-argumentais, considerando-se que o complemento dos supostos verbos de dois lugares é sempre um oblíquo. Esse tipo de predicado e os verdadeiramente monovalenciais são majoritários no corpus, com uma freqüência de: 38,0\% (36/94) para cada um; há 24,0\% (22/94) de predicados seguidos de SN predicativo, conforme se observa respectivamente em (20a-c).

(20) a. No Brasil, cerda de 100 mil casais por mês estão se beneficiando de um tratamento eficaz e seguro. (A, T81, L4)

b. Ela é a primeira com um exclusivo agente bactericida que mata germes e bactérias que se multiplicam na esponja. (A, T94, L5).

c. A pele já se torna mais firme. (A, T61, L9)

Tomando por base os subtipos de estados de coisas sugeridos por Kemmer, é possível identificar nos verbos de cuidado corporal, como vestir-se, nos de movimento não-translacional, como virar-se, e nos de mudança de postura corporal, como levantar-se, a característica semântica de acarretarem a fusão no sujeito dos papéis de Agente e Paciente, conforme aparece sugerido em Nunes (1995). O mesmo parece aplicar-se a outros tipos de situação que envolvem verbos de comportamento, como conduzir-se, comportar-se, portar-se. Verbos naturalmente recíprocos, como abraçar-se, parecem fundir os papéis de Agente e Beneficiário; observem-se, a esse propósito, as construções de (21a-b). 


\section{(21) a. João abraçou a mulher, antes que ela caísse de vez. \\ b. João abraçou-se à mulber, antes que (ele) caísse de vez.}

A sentença (21b) contém um verbo tipicamente médio cujo complemento preposicionado não funciona semanticamente como Beneficiário da ação de João, como é o caso do SN a mulher em (21a); funciona, muito provavelmente, como um Instrumento (meio de suporte), já que o Beneficiário passa a ser o próprio Agente, ambos fundidos no SN João na posição de sujeito.

Verbos inerentemente reflexivos, como suicidar-se, fundem Agente e Paciente. Os verbos ergativos derivados de causativos, como fechar-se, quebrar-se, incluindo os de processo psicológico, como assustar-se, impressionarse, irritar-se e outros não derivados de causativos, como arrepender-se, lembrar-se, esquecer-se, fundem os papéis de Paciente e Experienciador.

Em vez de falar em papéis temáticos ou funções semânticas, é preferível tratar essas relações como status conceituais mais generalizadores. Esses status conceituais podem incidir ou não sobre a função de sujeito de sentenças básicas, independentemente da atribuição de função semântica. Observe-se a sentença (22).

(22) Cigarro vende em qualquer lugar... mas é monopólio estatal (D2-RJ-355) ${ }^{6}$.

Nessa sentença, o SN cigarro representa uma entidade não-controladora, mas, como é o principal responsável pela atribuição da propriedade envolvida (entidade iniciadora), é a que ocupa a função sintática de sujeito. Esse exemplo mostra que a representação de um estado de coisas é independente de papéis temáticos tradicionalmente definidos, que representam escolhas alternativas para a posição de Sujeito.

Retomando os exemplos acima, vemos que todos envolvem a conceitualização do sujeito da sentença como o lugar de incidência do efeito do estado de coisas instaurado pelo predicado. A dupla identidade do sujeito decorre de a média instaurar uma perspectiva que representa a entidade afetada como o ponto de partida do evento e, portanto, iniciador

6 Para um tratamento exaustivo desse tipo específico de construção média, v. Rodrigues (1998) 
e/ou controlador ou, pelo menos, entidade não sujeita a qualquer causa externa.

As noções 'controlador' e 'entidade afetada' podem ser esclarecidas mediante uma comparação com os conceitos de 'Actor' e 'Undergoer', introduzidos por Foley \& Van Valin, (1984). Foley \& Van Valin definem 'Actor' como um macropapel, isto é, como um conceito hierarquicamente superior a relações temáticas como Agente, Instrumento, Objetivo e assim por diante. Analogamente, Foley \& Van Valin sugerem que há um outro macropapel, o de 'Undergoer', que fornece o protótipo do objeto básico.

Os argumentos que mantêm o macropapel 'Actor' têm em comum serem iniciadores potenciais e/ou controladores de estados de coisas expressos no predicado; o 'Undergoer', por outro lado, expressa o participante que não executa, inicia ou controla qualquer estado de coisas mas; ao contrário, é de algum modo afetado por ele.

Ao introduzir os conceitos de 'entidade afetada' e 'iniciador e/ou controlador', Klaiman (1988) distingue-os respectivamente dos macropapéis 'Actor' e 'Undergoer', considerando 'entidade afetada' e 'controlador não relações temáticas, mas status conceituais. Assim considerado, o status de entidade afetada pode acrescentar-se a argumentos representando várias relações temáticas e na verdade pode convergir com qualquer um dos dois macropapéis colocados por Foley \& Van Valin num argumento sentencial único.

Klaiman concorda com Foley \& Van Valin sobre a necessidade de macropapéis, mas não admite que o sistema de papéis atribua o status conceitual 'controlador' apenas ao macropapel 'Actor'. Na visão de Klaiman, 'Actor' e 'Undergoer' podem convergir num mesmo argumento da sentença, e essa convergência permite distinguir diferentes tipos de línguas.

Uma entidade afetada representa o participante percebido como afetado ou como o mais afetado em conseqüência do estado de coisas, ou como diz Klaiman, da 'ação sentencialmente denotada'. Uma entidade afetada não se submete necessariamente aos efeitos da ação, já que, em algumas línguas, um participante pode ser considerada afetado em virtude de executar certas ações. Embora o status conceitual de controlador seja ordinariamente associado ao macropapel 'Actor', ele pode acrescentar-se ao de 'Undergoer' em alguns sistemas. Por meio de uma definição opera- 
tória, o status de controlador pode ser atribuído ao argumento cuja participação é vista como determinando o curso e/ou o resultado de uma ação sentencialmente denotada.

\subsection{Construções médias: predicados de um só participante.}

A convergência dos status conceituais de iniciador/controlador e entidade afetada numa única entidade referencial na função de sujeito está correlacionada a outra propriedade semântica, ligada a um princípio denominado por Kemmer (1994) de 'relativa elaboração de eventos', um esquema mais generalizador, que retraduz a concepção de transitividade prototípica, sugerida por Givón (1994), com base no estudo sobre transitividade de Hopper \& Thompson (1980).

Apesar de sua generalidade, o esquema de Givón faz referência ao domínio pragmático, enfatizando a promoção do Paciente a tópico sentencial. Embora também presente na construção média, essa propriedade discursiva não é suficiente para identificar precisamente a distinção entre os domínios médio e reflexivo-recíproco, porque, por um lado, constituem tipos mais semânticos que pragmáticos de voz e, por outro, a promoção de paciente a tópico tem a ver com construções derivadas, como a passiva, e não com construções básicas de voz, como a média.

Como as línguas em geral assimilam outros tipos de eventos que não envolvem necessariamente transmissão de energia física, como os prototipicamente transitivos, Kemmer (1994) considera o grau em que a elaboração lingüística de um estado de coisas toma por base o ponto de vista de um participante que "inicia" o evento para um segundo participante, que é o alvo ou "ponto de chegada"; essas noções equivalem às de 'iniciador/controlador' e 'entidade afetada' de Klaiman (1988), mas não coincidem totalmente com elas. Kemmer argumenta em favor de uma princípio semântico que é crucial para a natureza da reflexividade e da medialidade. Esse princípio, ainda mais abrangente que a noção de afetação do sujeito, baseia-se numa escala ao longo da qual é possível situar a reflexividade e a medialidade não apenas como categorias semânticas intermediárias de transitividade entre eventos de um e de dois participantes, mas também como categorias distintas uma da outra. 
Com base num postulado de Haiman (1983) sobre a separação conceitual que o falante opera mentalmente no grau de individuação dos participantes, Kemmer (1994) elabora o parâmetro da distintividade relativa de participantes, segundo o qual uma entidade única físico-mental pode ser conceitualmente distinguida em diferentes participantes. O esquema abaixo representa essa escala:

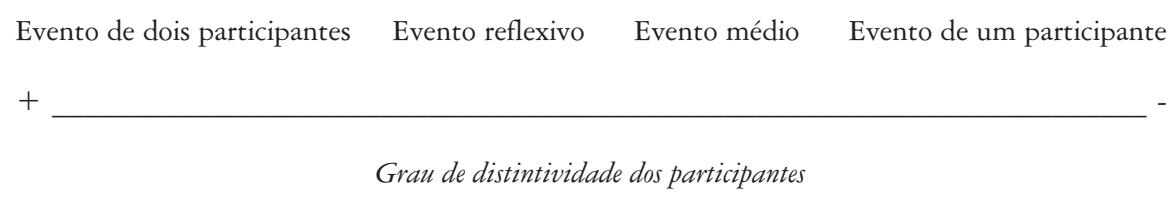

Um evento de dois participantes se caracteriza cognitivamente pela existência de dois distintos participantes preenchendo dois papéis semânticos numa interação ou relação assimétrica. Embora o evento reflexivo e o médio evoquem, como no evento de dois participantes, dois papéis semânticos separados, estes convergem para uma única entidade referencial. Em virtude dos distintos papéis que evocam, os eventos reflexivo e médio denotam relações internamente complexas, mas o primeiro implica uma diferenciação conceitual da entidade referencial em subpartes discretas, enquanto o segundo prescinde dessa diferenciação; desse modo, o evento médio está mais distante do evento de dois participantes que o reflexivo.

Dado que a função prototípica dos marcadores reflexivos é assinalar correferencialidade entre participantes que constituem entidades normalmente distintas, tem sentido analisar o evento reflexivo como o tipo de estado de coisas em que se mantém alguma separação entre Iniciador e Ponto de Chegada. Além disso, nos eventos reflexivos, o Iniciador atua sobre si mesmo do mesmo modo que atuaria sobre outra entidade dele distinta, e a função do marcador é simplesmente assinalar que diferentes papéis são exercidos pela mesma entidade. A função do marcador médio, ao contrário, é indicar que dois papéis semânticos, o de Iniciador e o de Ponto de Chegada, referem-se a uma entidade holística, destituída desses aspectos parciais e conceitualmente diferenciados (cf. Kemmer 1994: 207).

\subsection{De um sistema de marcação única para um sistema de marcação dupla.}

Como já mencionado, o marcador de voz média do português é, por definição, o clítico reflexivo; apesar disso, podem ocorrer alternativas nãoclíticas, mesmo num corpus mais formal, como as entrevistas do NURC: 
(23) a. todo o terreno da vizinhança já valorizou (D2-RJ-355)

b. o problema é vender pro comércio...quando começa a desenvolver o comércio... (D2-RJ-355)

c. o dia que você tiver verba pra consertar a torneira da tua escola... o vidro da janela que quebrou (D2-RJ-355)

d. quando atinge o quinto ano do primeiro grau é o grande deficit de evasão... é onde há... é o pique da evasão.. a pirâmide fecha ali... quase que fecha ali...(D2-RJ-355)

As sentenças acima não diferem semanticamente de suas alternativas clíticas; constituem com elas casos típicos de variação. Observe-se a esse propósito que o mesmo falante produz, às vezes, duas instâncias do mesmo predicado, ora clítico, ora não-clítico:

(24) acho que o sistema bancário já que nossa conversa é em torno de dinheiro... evoluiu muito e se popularizou [fechando o tópico] hoje popularizou o sistema bancário (D2-RJ-355)

Dados qualitativos extraídos da modalidade oral fornecem evidência adicional de que, à caracterização semântica própria de medialização, o PB falado vem acrescentando uma distinção gramatical relevante: somente construções médias permitem a supressão do clítico, que é nesse caso o morfema marcador, conforme se observa nos casos abaixo:

(25) a. Maria curvou um pouco mais para ver melhor o animal.

b. Maria ajoelhou para rezar.

Nos exemplos acima assinalados, aparecem predicados que representam movimento não-translacional (25a) e mudança na postura corporal (25b). Todos prescindem funcionalmente do clítico por duas razões: i) se não há objeto, a ação se volta para o sujeito, o que motiva um vestígio de reflexivo, que o clítico se ainda manifesta; ii) paradoxalmente, todavia, a intuição de que o clítico não funciona como autêntico reflexivo também torna gradualmente obsoleto seu uso.

Já com predicados agentivos que podem implicar intencionalidade e controle, como matar, a ausência do clítico na função reflexiva parece tornar completamente impensável a construção (26); entretanto, um equivalente semanticamente mais específico e tipicamente médio, como suicidar- 
se em (27), pode prescindir do clítico no registro informal da variedade falada.

(26) ?João matou (Ø) na semana passada.

(27) João (Ø) suicidou na semana passada.

Predicados de significado aproximado, como cortar e machucar, que não acarretam controle, são nitidamente ambíguos: (28a) e (29a) têm uma interpretação reflexiva, enquanto (28b) e (29b), uma interpretação medial:

(28) a. João se machucou gravemente para ganbar o seguro.

b. João (se) machucou gravemente podando a grama.

(29) a. João se cortou gravemente para ganhar o seguro.

b. João (se) cortou gravemente podando a grama.

Vários autores se dedicaram ao estudo do desaparecimento gradual dos clíticos pronominais acusativos de terceira pessoa no PB falado (cf. Duarte 1989 para uma perspectiva sincrônica; Cyrino 1996; Galves 1993 e Nunes 1995 para uma perspectiva diacrônica). No geral os autores que se debruçaram sobre o assunto se referem somente ao clítico não-reflexivo, com exceção de Nunes (1995). Num trabalho pioneiro sobre a supressão de clíticos reflexivos, D’Albuquerque (1984) compara o dialeto mineiro de Manhuaçu com o do Rio de Janeiro. Ao fornecer uma explicação sintática para a perda do reflexivo, inclui o processo no âmbito mais geral da perda de clítico marcador de objeto direto. É, todavia, suspeito, misturar casos como (30a-b):

$$
\begin{aligned}
& \text { (30) a. - Você viu o Joãozinho? } \\
& \text { - Vi . Está na casa do Zeca. } \\
& \text { b. Ela está maquiando. }
\end{aligned}
$$

A resposta contida em (30a) pressupõe a existência da entidade referencial Joãozinho e a supressão do clítico acusativo configura claramente um caso em que o antecedente está cotextualmente presente. A mesma explicação não se aplica ao predicado de (30b): a pressuposição é semânti- 
ca, não discursiva, e apenas revela que no sujeito convergem o controlador e a entidade semanticamente afetada pelos efeitos do estado de coisas verbalizado.

Mais apropriada é a explicação semântica em que a referida autora atribui a perda do clítico a reflexivos inerentes, cujo traço comum é a previsibilidade do objeto. Mencionando verbos como levantar, sentar, deitar, sustenta que seu uso transitivo não-reflexivo representa uma situação anômala, pois as situações mais comuns são aquelas em que "o agente é também o objeto da ação. Essa superposição de papéis semânticos é sentida como tão óbvia que a marca de reflexividade se torna desnecessária ao ponto de esvair-se" (D’Albuquerque 1984: 117-8).

Um aspecto curioso do cruzamento entre reflexividade e medialidade no português brasileiro são os verbos da classe de ferir, machucar, cortar, em que a afetação não atinge o agente como um todo, mas tão somente uma parte inalienável dele. Tais predicados, tipicamente ambíguos entre uma interpretação reflexiva e uma interpretação média, desenvolveram construções de objeto incorporado, que também ocorrem com predicados tipicamente mediais de cuidados corporais, como pentear-se:

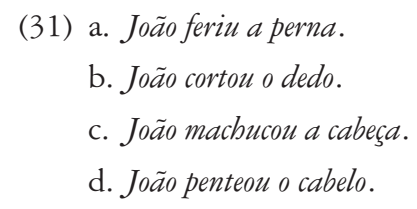

O sujeito nas construções de (31a-d) exerce papel de Experienciador e sua parte inalienável, papel de Meta (Paciente), como se o sujeito se desdobrasse em duas funções semânticas. Línguas como o francês tratam formalmente esses casos como construções típicas de voz, de acordo com o padrão: être + particípio + reflexivo. As construções equivalentes do português, que atribuem função de oblíquo ao $\mathrm{SN}$ referente à parte inalienável, soam demasiadamente formais, embora não estranhas:

(32) a. Jean s'est cassé la jambe (Vet 1985: 54)

b. João se feriu na perna.

Casos extremos de uso de construção ativa com sujeito afetado estão contidos em (33a-b) abaixo. 


\section{(33) a. João cortou o cabelo no José. \\ b. João operou o estômago com o Dr. Silva.}

Nesses casos, a estrutura SVO é apenas um simulacro de construção ativa; trata-se, na realidade, de uma construção de voz média sem o marcador se, que se vem popularizando no PB: assim, o sujeito e objeto representam uma espécie de entidade descontínua única, mas que se desdobra em todo e parte, na função de Beneficiário do estado de coisas, e o causativo não tem estatuto argumental, expressando-se na forma de oblíquo ${ }^{7}$.

Outros predicados de cuidado corporal, como banhar-se, barbear-se, que poderiam ser incluídos na categoria das construções médias, desenvolveram formas de expressão de verbo-suporte, como tomar banho, fazer a bar$b a$. É curioso que, em algumas línguas, o complemento verbal representando a parte do corpo afetada é freqüentemente especificado juntamente com a marcação medial, como por exemplo, na estrutura em francês il se lave les mains, uma formulação que, segundo Klaiman (1988) é similar à média do grego clássico. Quanto mais a parte inalienável estiver semanticamente prevista no radical verbal, menos provavelmente o objeto deverá receber especificação (Kemmer 1994).

Alguns verbos intransitivos de processo, como envelhecer, não se incluem no rol das construções médias. Um traço formal pertinente que dá suporte teórico a essa exclusão é não admitirem derivação lexical por redução de valência. Ao contrário, são as construções causativas correspondentes que constituem predicados derivados, mas por acréscimo de valência, conforme se vê em (34) abaixo.

(34) a. José envelheceu.

b. O excesso de trabalho envelheceu José.

Outros verbos monovalenciais, tipicamente intransitivos, como evoluir, regredir, prosperar, desaparecer, só admitem causatividade com o uso do auxiliar factitivo fazer. Entretanto, não é raro encontrar versões mediais desses predicados, como se observa em (35a-e), que são todos exemplares retirados da redação de vestibulandos.

7 Para uma discussão interessante da diátese de verbos como operar, v. Franchi \& Cançado, s/d. 
(35) a. O homem parece não estar se evoluindo, mas se regredindo cada dia mais.

b. Quando o sol se põe, as esperanças se desaparece no ar.

c. Um mundo onde a violência e a miséria se prospera cada dia mais.

d. A angústia se prolifera a cada hora que passa.

e. Ao percorrer os dias de minha vida, me amadureço e me faço mais lúcido.

Essas construções constituem casos de hipercorreção, que, como se sabe, é um fenômeno sociolingüístico motivado por um sentimento de insegurança em relação às normas gramaticais da variedade padrão. $O$ marcador de média ainda vigente, mas em franco processo de variação, possivelmente rumo ao desaparecimento, torna-se obrigatório no registro formal e se estende para formas que não o requerem, como os predicados monovalenciais intransitivos. Esse tipo de hipercorreção é resultado de um processo de analogia, cujo modelo são os predicados de processo, que parecem constituir o protótipo cognitivo da medialidade no português.

Essas correspondências sintático-semânticos encaminham a discussão para outro aspecto relevante, de natureza tipológica. A maioria das línguas dispõe de um marcador especial para indicar que a entidade iniciadora/controladora e a entidade afetada convergem no sujeito. A relação formal entre marcadores mediais e reflexivos mostra, segundo Kemmer (1994), ser possível separar as línguas com marcação medial num número limitado de classes tipológicas básicas.

Assim, há 'sistemas de uma forma' (one-form middle systems), que incluem o alemão e também línguas românicas, como o português, o espanhol e o francês; nesse tipo, o marcador medial é idêntico ao reflexivo. Num outro tipo de línguas, que se podem rotular 'sistemas de duas formas' (twoform middle systems), como o russo, o marcador de reflexividade (MR) é uma forma similar, mas não exatamente idêntica ao marcador de medialidade (MM). Geralmente, o MR é uma forma nominal ou pronominal, enquanto o MM é um afixo verbal, mas há línguas desse tipo em que ambos os marcadores são afixos verbais.

É comum em todas os sistemas de uma forma o MM apresentar menos substância fonológica que o MR, seja quanto ao número de segmentos, seja quanto ao grau de dependência fonológica com a raiz verbal; por isso, Kemmer as denomina respectivamente 'forma leve' (light form) e 'forma pesada' (heavy form) (cf. Kemmer, op.cit, p. 188). 
Nos eventos reflexivos, o Iniciador atua sobre si mesmo, como se atuasse sobre outra entidade, e o marcador reflexivo assinala tão somente o fato inusitado de que diferentes papéis temáticos são exercidos pela mesma entidade. Já nos eventos médios o marcador tem a função básica de indicar que dois papéis semânticos, o de Iniciador/Controlador e o de Entidade Afetada/Ponto de Chegada se referem a uma entidade singular holística (Kemmer 1994: 207) sem aspectos conceitualmente distintos. O peso fonológico mais leve do marcador médio reflete iconicamente o mais baixo grau de peso conceitual da entidade que ele sinaliza (cf. Haiman 1983; Kemmer 1994) ${ }^{8}$. É um tanto forçado chamar o clítico reflexivo de forma pesada, já que, em termos absolutos, é por definição átono e, portanto, foneticamente leve. Em termos relativos, entretanto, a forma pesada tem manifestação fonética, que estaria ausente na forma leve.

Esses padrões de marcação apontam para dois aspectos: por um lado, como os marcadores médio e reflexivo mostram freqüentemente correspondência formal sincrônica e/ou diacrônica, é possível concluir que há uma relação semântica entre as categorias que os marcadores expressam; por outro lado, a diferenciação semântica ou funcional entre as construções reflexiva e média também sugere uma distinção formal, suscetível de codificação lingüística, e é nos 'sistemas de duas formas' que a diferença se manifesta mais claramente (cf. Kemmer 1994: 190).

O latim se caracterizava como um 'sistema de duas formas', mas os marcadores reflexivo e médios não eram cognatos: a expressão formal do primeiro era o clítico se, enquanto a do segundo era desinencial, mediante o acréscimo de $-r$ à raiz verbal; nesse caso, o latim constituía um 'sistema de duas formas não cognatas' (two-form non-cognate system). O desaparecimento dos verbos depoentes, classe de media tantum, tornou possível generalizar o uso do clítico reflexivo também para as construções médias do português e de outras línguas românicas, como o espanhol e o francês.

Apesar dessa convergência formal das línguas românicas, é possível considerar a hipótese de que a distinção gramatical entre construções médias e reflexivas, presente no latim clássico, venha a traduzir-se, respecti-

8 Haiman (1983) trata a separação conceitual pressuposta nas formas leves e pesadas não como uma diferença entre a semântica reflexiva e a média, mas em termos do grau de 'individuação' de objetos, o que não é, todavia, incompatível com o princípio, já mencionado, da distintividade relativa de participantes de Kemmer(1994). 
vamente, na ausência e na presença do clítico. Nesse aspecto, o PB falado estaria numa fase mais avançada que o PE de desenvolvimento de um sistema de marcação dupla, similar ao do russo. Ao examinar dados do PE falado, Nunes entende que essa variedade está bem menos afeita à supressão de clíticos que a brasileira. "De certo modo", afirma, "o dialeto europeu parece espelhar estágios anteriores do português brasileiro" (Nunes 1995: 235).

Uma evidência que sustenta essa hipótese é o fato de que algumas variedades dialetais, comandadas pelo dialeto mineiro, chegam a substituir o clítico reflexivo por um pronome lexical:

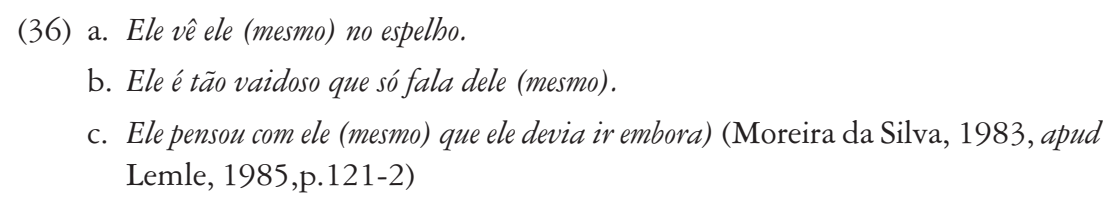

Em contraste, nos predicados médios inerentemente pronominais, esse pronome lexical pode ser simplesmente suprimido ou, variavelmente, manifestar-se também na forma tônica:

(37) Pedro está lavando (coçando, barbeando, vestindo) (ele) (Moreira da Silva, 1983, apud Lemle, 1985, p.121-2)

No dialeto mineiro, o pronome lexical comporta-se ora como pronome, ora como anáfora. Buscando explicação nos quadros da Teoria da Regência e da Vinculação, Galves (1986) entende que é a autonomia do pronome em relação à sintaxe que explica seu funcionamento aparentemente anafórico: ele não é o reflexivo de João, em (38), como seria a anáfora se, um caso de dependência referencial; em vez disso, ele e se remetem à mesma pessoa, o tópico do discurso, como uma conseqüência de ser o PB uma língua "de tópico" (Galves 1986: 254)

(38) João vê ele no espelho. (Galves, 1986: 250)

Essa variação entre ele e se na função reflexiva no dialeto mineiro, em contraste com a oposição entre ele/Ø na função medial, é um indício de que o processo de marcação está em mudança. Esse processo mostra, so- 
bretudo, que qualquer que seja a oposição inovadora, ela sempre põe em contraste formas leves e formas pesadas na mesma correlação, média $\mathrm{x}$ reflexivo.

Curiosamente o português difere tipologicamente das línguas clássicas IE, como o latim, o sânscrito e o grego, e se identifica mais com o tamil, uma língua dravídica do sul da Índia. Paramasivam (1977; 1979 apud Klaiman 1988) mostra que a diátese do tamil consiste tipicamente em uma alternância entre uma obstruinte simples e uma geminada a que se costuma referir como bases verbais 'fraca' e 'forte'. Não é necessário muito esforço para ver aqui os conceitos de forma 'leve' e forma 'pesada', cunhados por Kemmer (1994) e presentes no registro informal do português?.

Há uma diferença surpreendente entre o sistema das línguas clássicas IE e o do tamil, língua que se pode juntar o português: aquelas tratam o sujeito de ações recíprocas e reflexivas como entidades afetadas, de modo a definir duas funções típicas de voz média, além de outros tipos característicos; esta correlaciona essas construções com a diátese forte, nunca com a fraca, portanto, não como subfunções da média. É interessante observar que o tamil dispõe de formas fracas e formas fortes, que traduzem verbos de duas entradas lexicais do português, respectivamente, diátese média e ativo-transitiva, como juntar-se a alguém, juntar algo (como dinheiro, por exemplo)/ sentar alguém/ sentar-se ao lado de alguém, etc.

O português e o tamil se assemelham com base numa outra propriedade relevante: são línguas em que a entidade afetada invariavelmente tem o papel temático de fonte (actor) ou iniciador da ação verbalmente denotada. Embora as línguas clássicas IE conheçam essa mesma convergência ela não é absoluta, podendo, em certas circunstâncias, haver um descompasso entre a entidade iniciadora e a afetada ${ }^{10}$.

\footnotetext{
9 No geral, ocorre a forma fraca do verbo quando o efeito da ação se acrescenta ao sujeito, que é também a entidade iniciadora do estado de coisas; ocorre a forma verbal forte quando os principais efeitos da ação envolvem algum outro argumento.

10 Uma situação desse tipo aparece classificada sob a rubrica de função 'catalítica' da voz média grega (cf. Barber, 1975, apud Klaiman 1994). É como se sujeito catalisasse a ação, no caso, executada por uma outra entidade. Apesar de ser uma entidade separada a fonte da ação, o que determina a escolha da diátese média em lugar da ativa é ser o sujeito o principal 'locus dos efeitos da ação'.
} 


\section{Considerações Finais}

Como visto anteriormente, Benveniste caracteriza a diferenciação ativo/médio nas línguas clássicas IE, como a relativa participação da entidade na função de sujeito. Assim, na voz ativa, os verbos denotam um processo que se efetua a partir do sujeito e fora dele, enquanto, na voz média, o verbo indica um processo do qual o sujeito é a sede, estando no interior mesmo do processo. Na esteira de Benveniste, Barber (1975 apud Kemmer, 1994) e Klaiman (1988) entendem ser a afetação do sujeito o traço característico da média indo-européia, o que significaria restringir a categoria a predicações dinâmicas e não-controladas, que é como se caracterizam os verbos de processo. Um tratamento semelhante implicaria deixar de fora da categoria um grande número de verbos pronominais do português, alguns dos quais representam predicações dinâmicas e controladas (verbos de ação) e não-dinâmicas e controladas (verbos estativos de posição).

Na terminologia de Kemmer, o traço de afetação do sujeito se expande para abarcar a noção de que, nas médias processivas, os papéis de Iniciador (controlador ou fonte do estado de coisas) e o Ponto de Chegada (participante afetado) incidem necessariamente sobre a mesma entidade. Ao expandir-se, esse esquema de papéis pode ser transposto para outros tipos de construções em que Iniciador e Ponto de Chegada podem corresponder a outras funções semânticas e, desse modo, incluir também verbos de ação e de posição. É por isso que os casos de voz média não podem limitar-se apenas às construções de processo, como as ergativas, ainda que o esquema prototípico da média seja a convergência dos macropapéis Iniciador e Ponto de chegada na mesma entidade, o que identifica as construções processivas

Em suma, a construção de voz média do português acha-se formalmente relacionada à construção de voz reflexivo-recíproca em virtude da marcação comum com o clítico reflexivo; é, nesse aspecto, formalmente distante da passiva, que exige a formulação ser $+V-d 0^{11}$. Apesar disso, se o falante tomar, como ponto de vista para a construção da sentença, a entidade afetada, entendendo-a como diferenciada da entidade causadora, certamente a escolha recairá sobre uma formulação passiva. Se persistir a di-

\footnotetext{
11 A construção 'get-passive' do inglês, que representa conceitualmente a formulação mais próxima de uma construção média, tem forte ligação formal com a construção'be-passive'.
} 
ferenciação entre as duas entidades, mas o ponto de vista adotado for o da entidade instigadora do evento, a escolha recairá sobre uma construção ativa. A formulação medial só será selecionada se o estado de coisas for verbalizado do ponto de vista da entidade afetada, que também é a responsável pelo desencadeamento desse estado de coisas. Assim, a despeito da diferença formal, a construção média alterna funcionalmente com as demais construções de voz disponíveis no português.

Para concluir, uma nota pertinente sobre a conseqüência teórica das hipóteses aqui discutidas. Se válidas como se espera, parecem reforçar a idéia de que, ao ativar o princípio cognitivo de distintividade dos participantes, omitindo ou manifestando foneticamente o clítico, o falante aciona, correlativamente, o princípio de iconicidade, segundo o qual, quanto maior a distintividade, mais forte a marcação. Como um desdobramento dessa atividade cognitiva específica, sobressai o postulado funcionalista de que a gramática emerge do uso e, no caso da distinção entre construções médias e reflexivo-recíprocas, o uso das formas está voltado para a ativação de princípios semânticos dos quais a gramática parece ser não mais que uma conseqüência.

E-mail: camacho@tll.ibilce.unesp.br

Recebido em julho de 2002 Aprovado em outubro de 2002

\section{REFERÊNCIAS Bibliográficas}

Arce-Arenales, M. et al. 1994. Active voice and middle diathesis: a crosslinguistic perspective. In: Fox, B, Hopper, P.J. (eds.) Voice: form and function. Amsterdam/Philadelphia: John Benjamins: 1-22.

Bacelar do Nascimento, M. F., Martins, A.M.. s/d. Construções verbais portuguesas em -se médio observadas em textos medievais e em textos contemporâneos. Texto inédito não publicado.

Benveniste, E. 1976. Ativo e médio no verbo. In: Problemas de lingüistica geral. Trad. São Paulo: Editora Nacional/Editora da USP: 183-191.

CÂmara JR., J.M. 1972. Princípios de lingüística geral. Rio de Janeiro: Livraria Acadêmica, $4^{\mathrm{a}}$ ed. revista e aumentada. . 1977. Dicionário de Lingüística e Gramática. Petrópolis: Vozes. 
CyRINO. S. 1996. Observações sobre a mudança diacrônica no português do Brasil: objeto nulo e clíticos. In: I. Roberts, M. Kato (orgs.) Português brasileiro: uma viagem diacrônica. Campinas: Editora da UNICAMP: 163-84.

D’Albuquerque, A.C.R.C. 1984. A perda dos clíticos num dialeto mineiro. Tempo Brasileiro 78/79: 97-121.

Dik, S C. 1985. Formal and semantic adjustment of derived constructions. In: A. M. Bolkestein, C. de Groot, J.L Mackenzie (orgs.) Predicates and terms in Functional Grammar. Dordrecht-Holland/CinnaminsonUSA: Foris Publications: 1-28.

DuARTE, M.E.L. 1989. Clítico acusativo, pronome lexical e categoria vazia no português do Brasil. In: F. TARALlo (org.) Fotografias sociolingüísticas. Campinas: Pontes/Editora da UNICAMP: 19-34.

FRANCHI, C., CANÇADO, M. s/d. Reexame da noção de hierarquia temática. (Versão parcial e preliminar, sem revisão). Texto inédito, não publicado.

Galves, C. 1986. A interpretação "reflexiva" do pronome no português do Brasil. D.E.L.T.A. 2 (2): 249-264. . 1996. O enfraquecimento da concordância no português brasileiro. In: I. RoberTs, M. Kato (orgs.) Português brasileiro: uma viagem diacrônica. Campinas: Editora da UNICAMP: 387-408.

Givón, T. 1994. The pragmatics of de-transitive voice: functional and typological aspects of inversion. (Introduction). In: (ed.) Voice and Inversion. Amsterdam/Philadelphia: John Benjamins Publishing: 3-46.

Haiman, J. 1983. Iconic and economic motivation. Language 59: 781-819. Hopper, P. J., Thompson, S.A. 1980. Transitivity in grammar and discourse. Language 56: 51-299.

ILARI, R. et alii. 1996. Os pronomes pessoais do português falado: roteiro para a análise. In: A.T. CASTILHO, M. BAsílio (orgs.) Gramática do português falado (v.4: Estudos Descritivos). Campinas: Editora da UNICAMP; São Paulo: FAPESP: 79-168.

Kemmer, S. 1994. Middle voice, transitivity and the elaboration of events. In: B. Fox, P. J. Hopper (eds.) Voice: form and function. Amsteram/ Philadelphia: John Benjamins: 179-230.

Klaiman, M. H. 1988. Affectiveness and control: a typological study of voice systems. In: M. Shibatani (ed.) Passive and voice [Typological studies in language, v. 16] Amsterdam/Philadelphia: John Benjamins.

LemLe, M. 1985. Pronomes, anáfora, zero: observações sobre uma mudança lingüística. D.E.L.T.A. 1 (1/2): 121-124. 
LyONS, J.. 1979. Introdução à lingü̈́stica teórica. São Paulo: Nacional/EDUSP. Nunes, J. 1995. Ainda o famigerado se. D.E.L.T.A. 11 (2): 201-40.

Rodrigues, C.A.N. 1998. Aspectos sintáticos e semânticos das estruturas médias no Português do Brasil: um estudo comparativo. (Dissertação de Mestrado). Brasília: Universidade de Brasília.

Vet, C. 1985. Passive, reflexive, and causative predicate formation in French. In: A. M. Bolkestein, C. de Groot, J.L Mackenzie (orgs.) Predicates and terms in Functional Grammar.Dordrecht - Holland/ Cinnaminson-USA: Foris Publications: 49-69.

Whitaker-Franchi, R.C.M. 1989. As construções ergativas: um estudo sintático e semântico. Dissertação de mestrado. Campinas: IEL/UNICAMP. 